\title{
PENGARUH PEMUPUKAN TERHADAP PANJANG CABANG KESAMBI (Schleichera oleosa (Lour.) Merr.) DAN PRODUKTIVITAS LAK DI KPH PROBOLINGGO
}

\author{
Influence Fertilization on Length Branch of Kesambi (Schleichera oleosa (Lour.) Merr.) and \\ Producitvity of Shellac in KPH Probolinggo
}

\author{
Noor Farikhah Haneda ${ }^{1 *}$, Andi Sukendro ${ }^{1}$, Yuni Fatmasari ${ }^{2}$
}

(Diterima Desember 2019/Disetujui November 2020)

\begin{abstract}
Kesambi (Schleichera oleosa (Lour.) Merr.) is a host plant that becomes priority in lac culture in Indonesia. Shellac is one of the non-timber forest product commodities, which is potential to be one of foreign exchange sources. World demand of shellac is increasing throughout the year so that the improvement of shellac productivity is required to fulfill the demand. One of the alternatives is implementing the fertilization due to host plant quality improvement considering that host plant is the source of nutrient of shellac. The activity of fertilization aims to understand the effect of fertilization dosage to the improvement of the branch length as well as productivity of shellac in KPH Probolinggo. The greatest average value of branch length during three and six months, respectively were $66.48 \mathrm{~cm}$ and $83.24 \mathrm{~cm}$. While, the greatest average value of shellac productivity was $84.29 \mathrm{~g}$. The treatment of fertilization in different dosage to the kesambi (Schleichera oleosa (Lour.) Merr.) was not give significant effect to the length of branch as well as shellac productivity.
\end{abstract}

Keywords: fertilization, Kesambi, Shellac

\section{PENDAHULUAN}

Lak merupakan salah satu Hasil Hutan Bukan Kayu (HHBK) yang berasal dari resin hasil sekresi kutu lak (Laccifer lacca) pada jenis pohon tertentu (pohon kesambi, kaliandra dan akasia) yang diproses dan dijadikan sebagai pelapis kayu, pangan, kosmetik, perkakas perangkat keras, barang elektronik, obatobatan, dan tekstil (Radijanto 1999). Kesambi merupakan tanaman yang diprioritaskan sebagai inang dalam budidaya kutu lak di Indonesia. Kutu lak hidup menempel dan menghisap makanan dari tanaman inangnya. Setelah menempel pada cabang tersebut, kutu lak akan mengeluarkan sekresi berupa benang-benang putih untuk melindungi dirinya. Benang-benang putih tersebut akan semakin tebal dan sambung menyambung sehingga menutupi semua cabang. Benang-benang putih tersebut kemudian akan mengeras dan membentuk warna kuning keemasan yang bisa dipanen sebagai lak. Saat ini kebutuhan lak dunia mencapai 9000 ton dengan India sebagai pemasok utama sebesar 50\% (4 500 ton), di Indonesia komoditi lak belum diproduksi secara maksimal (Wulandari 2014).

Menurut Wibowo (2003), Lak menjadi salah satu komoditi hasil hutan bukan kayu yang sangat potensial sebagai salah satu sumber penghasil devisa negara. Produksi lak yang dihasilkan di Kabupaten Sumba Timur

\footnotetext{
${ }^{1}$ Dosen Departemen Silvikultur, Fakultas Kehutanan dan Lingkungan, Institut Pertanian Bogor

* Penulis korespondensi:

e-mail: nhaneda@yahoo.com

2 Mahasiswa Departemen Silvikultur, Fakultas

Kehutanan dan Lingkungan, Institut Pertanian Bogor
}

tahun 2012 dan 2013 mencapai 39 ton dan 47 ton ( Dinas Kehutanan Kab. Sumba Timur 2014). Sedangkan produksi lak yang dihasilkan di Probolinggo Jawa Timur pada tahun 2015 dan 2016 mencapai 182 ton dan 80 ton (Dinas Kehutanan Provinsi Jawa Timur 2017). Salah satu lokasi budidaya kutu lak di Indonesia terdapat di Kesatuan Pemangkuan Hutan (KPH) Probolinggo Perum Perhutani Divisi Regional Jawa Timur, yaitu di Bagian Kesatuan Pemangkuan Hutan (BKPH) Kabuaran dan Taman. Hasil produksi kutu lak di KPH Probolinggo tidak dapat memenuhi permintaan pasar karena budidaya yang dilakukan masih tradisional. Oleh karena itu penelitian mengenai peningkatan produksi lak perlu dilakukan. Salah satunya dengan kegiatan pemupukan untuk meningkatkan kualitas inang yang menjadi sumber nutrisi bagi kutu lak. Penelitian ini menggunakan metode dengan menggabungkan penggunaan pupuk organik dan pupuk anorganik, sehingga dapat diperoleh informasi peningkatan produksi lak untuk pengelolaan budidaya kutu lak yang lebih baik dengan pemupukan.

Adapun tujuan dari penelitian ini adalah untuk mengetahui kegiatan budidaya kutu lak dan mengetahui pengaruh dosis pemupukan terhadap pertumbuhan panjang cabang serta produksi kutu lak di KPH Probolinggo.

\section{METODE PENELITIAN}

\section{Waktu dan Tempat Penelitian}

Penelitian ini dilaksanakan selama 6 bulan yaitu pada bulan Desember 2015 sampai dengan Mei 2016. Lokasi penelitian yaitu di BKPH Kabuaran, KPH Probolinggo, Perum Perhutani Divisi Regional Jawa Timur. 


\section{Alat dan Bahan}

Alat yang digunakan dalam penelitian ini adalah timbangan, cangkul, pita meter, alat tulis, spidol permanen, plastik mika, hekter, gunting, karung, tali rafia, kantong plastik, dan trashbag. Bahan yang digunakan dalam penelitian ini adalah kompos, pupuk urea, $\mathrm{KCl}$, TSP, kantong tularan kutu lak, dan pohon kesambi usia \pm 47 tahun.

\section{Prosedur Penelitian}

\section{Budidaya kutu lak}

Pengambilan data dilakukan melalui wawancara dan diskusi untuk mengumpulkan informasi dari narasumber yaitu para pegawai dan staf karyawan di KPH Probolinggo. Selain itu dilakukan pengambilan data sekunder yang berisi tentang informasi budidaya kutu lak.

\section{Pembuatan petak pengamatan}

Satu petak pengamatan berukuran $20 \mathrm{~m}$ x $20 \mathrm{~m}$ yang mencakup 7 pohon Copies system. Copies system merupakan teknik penebasan pohon inang setinggi dada yang dilakukan untuk memudahkan dalam proses penularan dan panen kutu lak. Jumlah petak ada sebanyak tiga petak dengan pemberian dosis yang berbeda. Petak satu merupakan kontrol yang tidak diberi pupuk, petak dua merupakan pohon yang diberi kompos $10 \mathrm{~kg}$, dan TSP, KCl, Urea masing-masing $100 \mathrm{~g}$. Petak tiga merupakan pohon yang diberi kompos $5 \mathrm{~kg}$, dan TSP, $\mathrm{KCl}$, Urea masing-masing $50 \mathrm{~g}$.

\section{Pemberian pupuk}

Pohon pengamatan ditandai dan diberi nomor. Selanjutnya dilakukan pembebasan tumbuhan bawah dan liana yang terdapat di sekitar pohon, kemudian tanah digemburkan dan diberi kompos serta pupuk urea, $\mathrm{KCl}$, TSP diatasnya secara melingkar dengan jari-jari $50 \mathrm{~cm}$ dari batang pohon. Kemudian ditutupi tanah, hal ini bertujuan agar pupuk yang diberikan tidak larut dan terbawa oleh aliran air hujan.

\section{Pengukuran panjang cabang}

Pengukuran cabang seperti yang disajikan pada Gambar 1 dilakukan sebanyak tiga cabang pada masingmasing pohon, yang diukur pada 0 bulan, 3 bulan, dan 6 bulan. Pengukuran menggunakan pita meter, galah, dan meteran.

\section{Panen kutu lak}

Waktu panen dilakukan 5-6 bulan setelah penularan kutu lak pada inang dengan memotong bagian cabang yang menghasilkan lak. Pengamatan dilakukan dengan menimbang berat lak cabang yang dipanen.

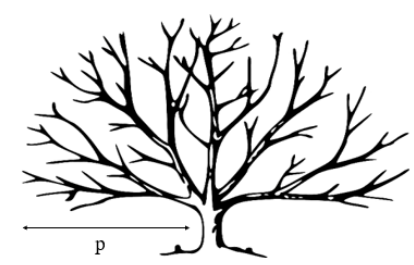

Gambar 1 Pengukuran panjang cabang (p)

\section{Rancangan Percobaan}

Penelitian ini menggunakan Rancangan Acak Lengkap (RAL) satu faktor yaitu dosis pemupukan, serta panjang cabang dan produksi lak sebagai responnya. Faktor tersebut terdiri atas tiga perlakuan dan terdapat tujuh ulangan sehingga percobaan dibutuhkan 21 pohon kesambi.

Perlakuan berupa dosis pupuk terdiri atas:

A1 : Tidak diberi pupuk (kontrol)

A2 : Kompos $10 \mathrm{~kg}+\mathrm{TSP} 100 \mathrm{~g}+\mathrm{KCl} 100 \mathrm{~g}+$ Urea $100 \mathrm{~g}$

A3 : Kompos $5 \mathrm{~kg}+\mathrm{TSP} 50 \mathrm{~g}+\mathrm{KCl} 50 \mathrm{~g}+$ Urea $50 \mathrm{~g}$

Keterangan:

$$
Y_{i j}=\mu+\mu_{i}+\varepsilon_{i j}
$$

$\mathrm{Y}_{\mathrm{ij}}=$ Respon percobaan pada unit percobaan yang dikenai perlakuan ke-i dan ulangan ke-j

$\mu \quad=$ rata-rata umum

$\mu_{\mathrm{i}} \quad=$ pengaruh perlakuan ke-i

$\varepsilon_{\mathrm{ij}}=$ sisaan acak pada unit percobaan yang dikenai perlakuan ke-i dan ulangan ke-j

Hipotesis yang dapat diambil untuk diuji dalam penelitian ini adalah:

Pengaruh utama faktor dosis pupuk

$\mathrm{H}_{0}: \alpha_{1}=\alpha_{2}=\ldots=\alpha_{\mathrm{a}}=0$ (tidak ada pengaruh faktor dosis pupuk terhadap panjang cabang dan produktivitas lak)

$H_{1}$ : paling sedikit ada satu perlakuan dengan $\alpha_{g} \neq 0$ (ada pengaruh faktor dosis pupuk terhadap panjang cabang dan produktivitas kutu lak)

\section{Analisis Data}

Analisis sidik ragam dengan uji $\mathrm{F}$ dilakukan untuk mengetahui pengaruh perlakuan dalam penelitian ini. Data diolah dengan menggunakan software SAS 91. Jika:

a. Nilai P-value > $\alpha(0.05)$, maka perlakuan tidak memberikan pengaruh nyata terhadap produktivitas lak dan panjang cabang.

b. Nilai P-value $<\alpha$ (0.05), maka perlakuan memberikan pengaruh nyata terhadap produktivitas lak dan panjang cabang, lalu dilanjutkan dengan uji lanjut Duncan's Multiple Range Test.

\section{HASIL DAN PEMBAHASAN}

\section{Budidaya kutu lak}

Kutu lak (Laccifer lacca Kerr) adalah jenis serangga yang termasuk famili Kerriidae ordo Hemiptera dan hidup secara parasitik. Kutu lak hidup pada tanaman kesambi (Scheichera oleosa Merr) selama 20-22 minggu. Telur terdapat di dalam tubuh induknya yang berkulit keras. Telur menetas menjadi nimfa yang bergerak mencari makan secara aktif dan pasif. Nimfa akan menetap secara permanen pada bagian cabang tanaman dan berganti kulit serta mereduksi organ antena dan tungkai (Rostaman 2009). Kutu lak memakan gubal cabang muda dari tanaman inangnya dan 
mengeluarkannya dalam bentuk sekresi (kotoran) yang disebut lak. Kutu lak hidup menempel dan menghisap makanan dari tanaman inangnya. Tanaman yang dapat digunakan sebagai inang yaitu kesambi, ploso, dan akasia (Wulandari 2012). Menurut Suita (2012), kesambi merupakan salah satu jenis pohon yang dapat dijadikan sebagai tempat memelihara, mengembangkan dan menularkan kutu lak. Kesambi mengeluarkan cairan lebih banyak untuk pakan kutu lak sehingga kutu lak lebih cepat berkembang biak dan kualitas lak yang dihasilkan lebih baik. Setelah kutu lak menempel pada cabang tersebut, kutu lak akan mengeluarkan sekresi berupa benang-benang putih untuk melindungi dirinya. Benang-benang putih tersebut akan semakin tebal dan sambung menyambung sehingga menutupi semua cabang. Benang-benang putih tersebut kemudian akan mengeras dan membentuk warna kuning keemasan yang bisa dipanen sebagai lak dengan cara memotong 10-15 cm cabang tanaman.

Tahapan yang dilakukan dalam budidaya kutu lak diantaranya persiapan lapangan, persiapan bibit lak, tularan, pemeliharaan tularan, dan unduhan. Kegiatan persiapan lapangan meliputi pembuatan blok seluas 2-4 ha untuk memudahkan administrasi tularan. Selanjutnya dilakukan babat tumbuhan bawah untuk membasmi sarang penyakit dan predator, sekaligus untuk menjaga sirkulasi udara pada saat tularan dilaksanakan. Wiwil dan pemangkasan dilakukan pada cabang yang tidak sehat, kemudian dilakukan pemupukan dan penyiraman terhadap inang yang kurang sehat atau mengalami gugur daun sehingga tidak mengalami kegagalan pada saat tularan. Pada tahap ini juga dapat dilakukan pengkayaan jenis tanaman inang dan penempatan lokasi tularan berdasarkan musim dengan cara membuat zonasi bulan basah dan bulan kering. Penempatan lokasi ini sangat penting untuk menentukan lokasi yang akan ditulari.

Kegiatan yang dilakukan pada tahap persiapan bibit lak adalah seleksi bibit. Seleksi bibit merupakan kegiatan yang menentukan keberhasilan tularan pada proses tularan. Ada beberapa hal yang perlu diperhatikan untuk keberhasilan dalam pelaksanaan tularan diantaranya penentuan kelas pohon, teknik penularan, ketepatan

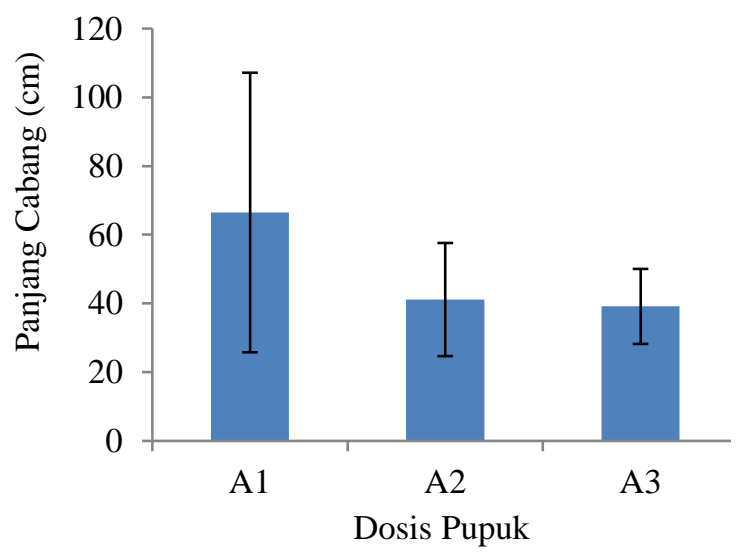

Gambar 2 Rata-rata pertambahan panjang cabang pada waktu tiga bulan (A1: Tanpa pupuk; A2 : kompos $10 \mathrm{~kg}+$ TSP $100 \mathrm{~g}$ + KCl $100 \mathrm{~g}+$ Urea $100 \mathrm{~g}$; A3: kompos $5 \mathrm{~kg}+\mathrm{TSP} 50 \mathrm{~g}+\mathrm{KCl} 50 \mathrm{~g}+$ Urea $50 \mathrm{~g}$ ) waktu pungutan bekas bibit. Penentuan kelas pohon dilakukan untuk menentukan jumlah kantong bibit yang akan ditulari. Penentuan kelas pohon dilakukan dengan melihat jumlah cabang setiap pohonnya, semakin banyak jumlah cabang suatu pohon maka jumlah kantong tularan juga semakin banyak. Selanjutnya dilakukan tularan kutu lak pada inang. Teknik dalam penularan dilakukan dengan penempatan bibit pada posisi sejajar dan sedekat mungkin dengan cabang muda. Kemudian pungutan bekas bibit lak yang dilaksanakan pada tularan umur tiga minggu dengan ketentuan satu per tiga sampai satu per dua bagian dari cabang sudah ditempeli larva lak, kantong bibit tidak boleh dibuka pada lokasi tularan, pungutan bekas bibit ditimbang untuk mengetahui rendemen produksi lak cabang.

Setelah kutu lak menempel pada pohon inang harus dilaksanakan pemeliharaan tularan agar kutu lak yang baru menempel pada pohon inang dapat membentuk sekresi baru tanpa adanya gangguan. Kegiatan yang dilakukan pada tahap pemeliharaan tularan diantaranya babat tumbuhan bawah, pengasapan, pemupukan dan penyiraman. Babat tumbuhan bawah dilakukan untuk membersihkan tumbuhan liar di bawah tegakan pohon yang mengganggu keberadaan tularan kutu lak, sekaligus membasmi sarang parasit dan predator. Pengasapan dilakukan dengan membakar sisa-sisa babat tumbuhan bawah. Pengasapan dilakukan untuk membuat suhu yang optimal bagi larva lak. Pelaksanaan pengasapan harus memperhatikan arah mata angin sehingga asap yang ditimbulkan dapat mengarah pada lokasi tularan. Pemupukan dan penyiraman juga dapat dilakukan pada tahap pemeliharaan tularan.

Kegiatan yang dilakukan pada tahap unduhan lak cabang diantaranya pemangkasan, pemotongan lak cabang, angkutan lak cabang, dan seleksi lak cabang. Sebelum dilaksanakan pemangkasan terlebih dahulu dilakukan pemberian tanda pada pohon yang akan diunduh. Pemangkasan cabang dilakukan $\pm 15 \mathrm{~cm}$ dari pangkal tunas. Selanjutnya dilakukan pemotongan lak cabang sepanjang 10-15 cm. Setelah dipotong lak cabang

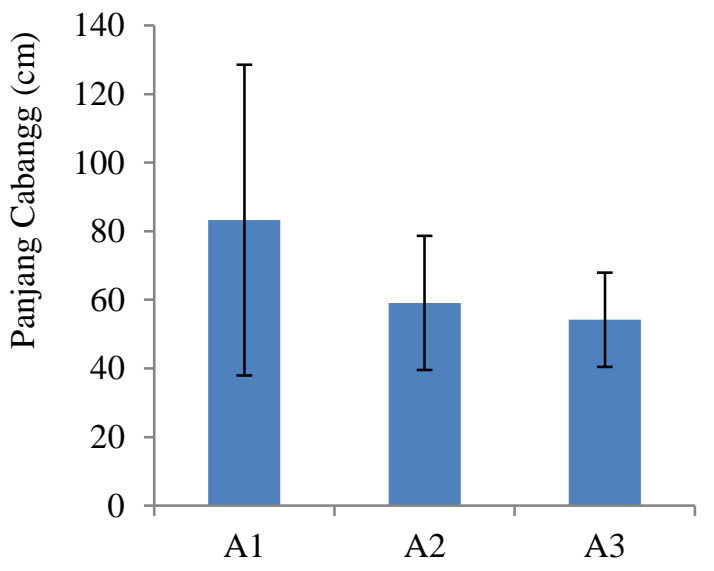

Dosis Pupuk

Gambar 3 Rata-rata pertambahan panjang cabang pada waktu enam bulan (A1: Tanpa pupuk; A2: kompos $10 \mathrm{~kg}+$ TSP $100 \mathrm{~g}+$ $\mathrm{KCl} 100 \mathrm{~g}+$ Urea $100 \mathrm{~g}$; A3: kompos $5 \mathrm{~kg}$ + TSP $50 \mathrm{~g}+\mathrm{KCl} 50 \mathrm{~g}+$ Urea $50 \mathrm{~g}$ ) 
dimasukan kedalam karung untuk diangkut ke gudang. Pengangkutan dilaksanakan dengan menggunakan kendaraan bak tertutup agar kutu lak tidak terkena sinar matahari langsung. Lak cabang kemudian diseleksi dan dipisahkan antara yang produksi dan untuk bibit.

\section{Pengaruh dosis pupuk terhadap pertambahan panjang cabang}

Hasil analisis sidik ragam menunjukan bahwa dosis pupuk tidak berpengaruh nyata terhadap pertambahan panjang cabang pada waktu tiga bulan dan enam bulan setelah perlakuan. Rata-rata pertambahan panjang cabang pada waktu tiga bulan dan enam bulan disajikan pada Gambar 2 dan Gambar 3.

Rata-rata panjang cabang yang dihasilkan setelah tiga bulan perlakuan menunjukan bahwa rata-rata tertinggi pada perlakuan A1 sebesar $66.48 \mathrm{~cm}$ dan ratarata panjang cabang terendah pada perlakuan A3 sebesar $39.14 \mathrm{~cm}$. Sementara rata-rata pertambahan panjang cabang setelah enam bulan perlakuan menunjukan bahwa rata-rata tertinggi pada perlakuan A1 sebesar $83.24 \mathrm{~cm}$ dan rata-rata panjang cabang terendah pada perlakuan A3 sebesar $54.18 \mathrm{~cm}$.

Mutu lak yang tinggi ditentukan oleh teknik kultur lak yang baik, salah satu diantaranya adalah teknik penanaman atau persiapan inang dilapangan, sehingga kondisi inang juga menentukan produktivitas lak yang dihasilkan. Produktivitas lak bergantung pada inang sebagai media tularan bagi kutu lak. Peningkatkan kondisi inang dilakukan melalui kegiatan pemeliharan yaitu pemupukan. Pemupukan dilakukan untuk meningkatkan kualitas inang dengan mengukur pertambahan panjang cabang. Namun demikian pemupukan ternyata tidak berpengaruh terhadap pertambahan panjang cabang pada waktu tiga dan enam bulan. Hal ini diduga karena adanya faktor lain yang mempengaruhi pertambahan panjang cabang pada pohon inang. Menurut Jumin (2005) setiap tanaman memiliki respon yang berbeda terhadap pemupukan, hal tersebut dikarenakan adanya pengaruh faktor iklim maupun faktor tanah dan tanaman. Salah satunya adalah usia tanaman yang dapat mempengaruhi kemampuan inang dalam menyerap unsur hara. Seperti yang dikemukakan oleh Rosmarkam (2002) bahwa kecepatan penyerapan unsur hara umumnya menurun dengan bertambahnya umur tanaman. Pada pohon yang semakin tua organorgan penyerap unsur hara seperti akar akan semakin melemah dan fungsinya semakin menurun. Akar merupakan struktur tumbuhan yang terdapat didalam tanah sebagai tempat masuknya mineral atau zat-zat hara dari tanah menuju ke seluruh bagian tumbuhan. Air dan mineral dari tanah masuk ke tumbuhan melalui ujung akar dan rambut-rambut akar menuju ke pembuluh kayu. Usia inang yang mencapai 47 tahun diduga mempengaruhi kemampuan akar menjadi semakin menurun, sehingga unsur hara yang masuk kedalam tumbuhan semakin berkurang.

Menurut Aak (1997) akar memiliki beberapa bagian diantaranya kulit luar (epidermis), kulit pertama (endodermis), dan silinder pusat. Di ujung akar terdapat sel-sel epidermis yang berbentuk pipa dan menjulang keluar. Sel-sel ini menjadi bulu akar yang menembus kedalam bagian tanah yang terkecil. Bulu akar hanya terdapat disekitar ujung-ujung akar. Bulu akar adalah bulu-bulu atau rambut berbentuk serabut halus pada akar tumbuhan, biasanya berukuran kecil dan terdapat pada sisi-sisi akar utama atau percabangan akar. Rambut akar merupakan perluasan permukaan dari lapisan epidermis akar yang berfungsi untuk mengoptimalkan penyerapan air dan mineral. Semakin banyak rambut akar maka luas permukaan akar akan semakin besar, sehingga memungkinkan tumbuhan untuk menjangkau air dan mineral hara ditempat yang jauh. Menurut Lestari (2011) akar lateral adalah bagian organ yang penting peranannya bagi pertumbuhan tanaman karena pada bagian tanaman ini terdapat bulu-bulu akar yang berfungsi untuk menyerap air dan unsur hara dari dalam tanah. Pohon yang tua memiliki akar lateral yang besar dan lebar. Sementara pemupukan dilakukan di sekitar batang pohon. Hal ini dapat menyebabkan bulu-bulu akar pada ujung akar tidak dapat menjangkau pupuk yang diberikan di sekitar batang pohon. Akar yang semakin tua memiliki kulit akar tebal dan sulit ditembus oleh air, sehingga luas penyerapan air dan mineral oleh akar akan berkurang.

Selain kondisi tanaman teknik pemupukan juga dapat berpengaruh terhadap panjang cabang. Menurut Agromedia (2007) pemupukan tidak selalu memberikan jaminan kesuburan bagi tanaman, karena pemupukan yang keliru akan menyebabkan dampak yang buruk pada tanaman. Beberapa pemahaman sebelum dilakukan pemupukan diantaranya jenis dan dosis pupuk. Atmosoedarjo et al. (2000) mengungkapkan bahwa pupuk kimia atau anorganik mudah dalam penggunaannya dan hasilnya cepat terlihat, tetapi sukar untuk memperbaiki tanah dan mempertahankan produktivitasnya. Sebaliknya pupuk organik dapat meningkatkan kesuburan tanah, sehingga dapat dilakukan pemupukan menggunakan keduanya dengan dosis yang tepat. Pupuk yang diberikan harus sesuai dengan kebutuhan tanaman untuk menghasilkan produktivitas dan pertumbuhan yang maksimal bagi tanaman. Menurut Rukmana (2004) dosis pupuk yang tepat didasarkan pada hasil analisis tanah atau tanaman, atau mengacu kepada pendekatan fase pertumbuhan tanaman. Ada dua fase pertumbuhan tanaman untuk pemupukan diantaranya fase tanaman muda dengan umur pohon dibawah tiga tahun, dan fase dewasa dengan umur pohon diatas tiga tahun. Pemupukan dilakukan dengan dosis pupuk yang mengacu pada pendekatan fase pertumbuhan tanaman dewasa secara umum, sehingga diduga dosis yang diberikan kurang atau tidak sesuai dengan unsur hara yang dibutuhkan oleh tanaman. Hal ini menyebabkan pemupukan tidak berdampak nyata pada pertambahan panjang cabang.

Adapun faktor lingkungan berupa gangguan dari masyarakat. Rata-rata pertambahan panjang cabang menunjukan perlakuan kontrol lebih baik dibandingkan dengan perlakuan lainnya pada waktu tiga bulan dan enam bulan. Hal ini diduga karena adanya gangguan dari masyarakat yang melakukan tumpangsari pada lokasi inang yang diberi pupuk. Masyarakat dengan sengaja memotong dan memangkas cabang untuk memenuhi kebutuhan cahaya tanaman tumpangsari, sehingga kondisi cabang dengan perlakuan kontrol lebih baik dibandingkan dengan perlakuan lainnya. 


\section{Pengaruh dosis pupuk terhadap produktivitas kutu} lak

Hasil analisis sidik ragam pengaruh dosis pupuk terhadap produktivitas kutu lak menunjukkan tidak ada pengaruh yang signifikan $(\mathrm{p}>0.05)$. Rata-rata produktivitas lak pada setiap perlakuan disajikan pada Gambar 4.

Rata-rata produktivitas lak (Gambar 4) yang dihasilkan menunjukan bahwa produktivitas lak tertinggi pada perlakuan A2 sebesar $150 \mathrm{~g}$ dan produktivitas terendah pada perlakuan A1 sebesar $84.29 \mathrm{~g}$.

Dosis pupuk tidak berpengaruh terhadap produktivitas kutu lak. Hal ini dapat diduga karena adanya faktor lain yang mempengaruhi kondisi inang. Tanaman inang sebagai media penularan kutu lak perlu dibudidayakan dengan baik untuk memperoleh tegakan yang sehat dengan percabangan yang kompak atau baik pada pertumbuhan kutu lak, dan untuk meningkatkan kemampuan bertunas dan pembentukan cabang atau cabang harus dilakukan kegiatan pemeliharaan berupa wiwil, babat tumbuhan bawah, pendangiran dan pemupukan. Keberhasilan budidaya kutu lak ditentukan oleh kualitas bibit, cara pemeliharaan, cara penularan, serta tata waktu penularan (Perhutani 1987). Selain itu Wulandari (2014) mengemukakan bahwa penyebab kegagalan berkembangnya kutu lak dapat disebabkan oleh mekanisme alamiah berupa suhu, cahaya matahari, angin dan hujan. Kondisi tanaman inang yang terlalu rimbun atau lembab juga sangat berpengaruh karena dapat menyebabkan tidak adanya aliran angin kedalam tularan, dan tidak terkena sinar matahari secara cukup.

Kualitas inang mempengaruhi produktivitas lak dalam penyediaan media tularan dan menjadi sumber makanan bagi kutu lak yang ditularkan, sehingga pemupukan yang tidak berpengaruh nyata terhadap pertambahan panjang cabang berbanding lurus dengan pengaruh pemupukan yang tidak berpengaruh nyata terhadap produktivitas lak. Nutrisi yang masuk tidak dapat memenuhi kebutuhan makanan kutu lak sehingga

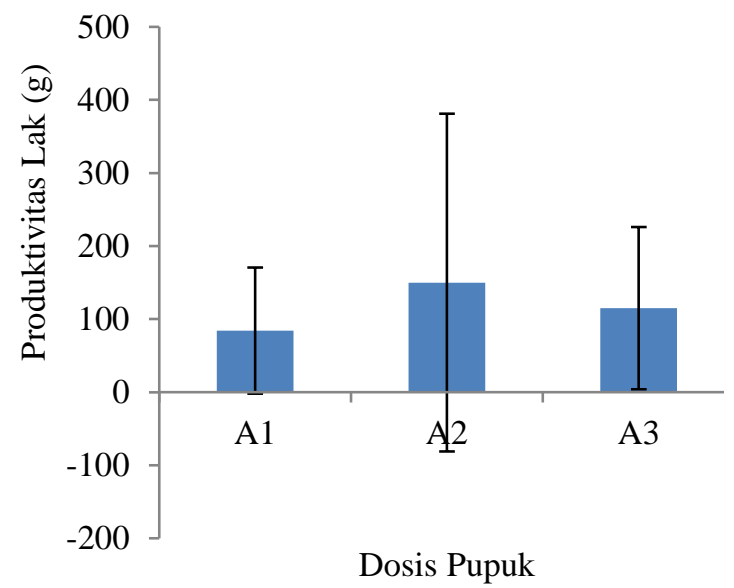

Gambar 4 Rata-rata produktivitas lak (A1: Tanpa pupuk; A2: kompos $10 \mathrm{~kg}+$ TSP $100 \mathrm{~g}$ $+\mathrm{KCl} 100 \mathrm{~g}+$ Urea $100 \mathrm{~g}$; A3: kompos $5 \mathrm{~kg}+\mathrm{TSP} 50 \mathrm{~g}+\mathrm{KCl} 50 \mathrm{~g}+$ Urea $50 \mathrm{~g}$ ) produktivitas lak menjadi rendah. Rata-rata produktivitas lak (Gambar 4) menunjukan bahwa perlakuan A2 lebih tinggi dibandingkan dengan perlakuan lainnya. Hal ini menunjukan bahwa pemupukan dapat memberikan nutrisi lebih banyak pada inang sebagai media tularan kutu lak.

\section{SIMPULAN DAN SARAN}

\section{Simpulan}

Perlakuan pemupukan pada kesambi dengan dosis yang berbeda tidak memberikan pengaruh nyata terhadap pertambahan panjang cabang. Rata-rata pertambahan panjang cabang paling baik pada waktu tiga dan enam bulan adalah perlakuan kontrol. Hal ini disebabkan karena pertambahan panjang cabang dipengaruhi oleh kondisi inang yang sudah tua sehingga memengaruhi fisiologinya juga melambat, faktor lingkungan dan teknik pemupukan. Sementara perlakuan pemupukan dengan dosis yang berbeda tidak berpengaruh nyata juga terhadap produktivitas kutu lak. Hal ini dipengaruhi oleh kualitas bibit, cara pemeliharaan, cara penularan, tata waktu penularan dan usia inang yang sudah terlalu tua. Rata-rata produktivitas lak paling tinggi adalah perlakuan pupuk dengan dosis kompos $10 \mathrm{~kg}+\mathrm{TSP} 100 \mathrm{~g}+\mathrm{KCl} 100 \mathrm{~g}+$ Urea $100 \mathrm{~g}$.

\section{Saran}

Perlu dilakukan kegiatan regenerasi tanaman kesambi untuk meningkatkan kualitas inang sebagai pakan kutu lak, karena inang yang ada sudah tidak produktif lagi dan umurnya sudah tua yaitu sekitar 47 tahun.

\section{DAFTAR PUSTAKA}

Aak. 1997. Budi daya Durian. Yogyakarta (ID): Kanisius.

Agromedia. 2007. Petunjuk Pemupukan. Jakarta(ID): PT Agromedia Pustaka.

Atmosoedarjo H, Pramoedibyo R. 2000. Sutera Alam Indonesia. Jakarta (ID): Yayasan Sarana jaya.

Daniel TW, Helms JA, Baker FS. 1987. Prinsip-Prinsip Silvikultur. Marsono D, Penerjemah: Soeseno OH, editor. Yogyakarta (ID): Gadjah Mada University Press.

Dinas Kehutanan Provinsi Jawa Timur. 2017. Produksi Hasil Hutan Non Kayu Menurut Jenis Produksi. Surabaya (ID). Dinas Kehutanan Provinsi Jawa Timur.

Dinas Kehutanan Sumba Timur. 2004. Catatan Produksi lak Kabupaten Sumba Timur. Waingapu (ID). Dinas Kehutanan Sumba Timur.

Jumin HB. 2005. Dasar-Dasar Agronomi. Jakarta (ID): Raja Grafindo Persada.

Lestari D. 2011. Perbaikan pertumbuhan tanaman rasamala (Altingia excelsa Noronhae) dengan teknik Lateral Root Mapinulation (LRM) di hutan 
pendidikan gunung walat, kabupaten Sukabumi [skripsi]. Bogor (ID): Institut Pertanian Bogor.

Perum perhutani. 1987. Pedoman Pengusahaan Klas Perusahaan Lak. Jakarta (ID): Perum Perhutani

Pakan S. 2007. Pelapis Pangan Alami Asal Lak: Kondisi Saat Ini dan Potensi Pengembangan di Propinsi Nusa Tenggara Timur. Ulasan Ilmiah. 18(2):142147.

Radijanto SS. 1999. Model untuk Penaksiran Lak pada Tanaman Inang Schleichera eleosa Merr V(31). Jakarta (ID): Perum Perhutani.

Rosmarkam A, Yuwono NW. 2002. Ilmu Kesuburan Tanah. Yogyakarta (ID): Kanisius.

Rostaman, Suryatna B. 2009. Evaluasi Produktivitas Kutu lak, Laccifer lacca Kerr (Hemiptera: Kerridae) pada Tiga Jenis Tanaman Inang. Entomologi Indonesia. 6(2):70-76.
Rukmana H. 2004. Seri Budidaya Leci, Potensi dan Peluang Agrobisnis. Yogyakarta (ID): Kanisius.

Suita E. 2012. Seri Teknologi Perbenihan Tanaman Hutan. Bogor (ID): Balai Penelitian Teknologi Perbenihan Tanaman Hutan.

Sunanto H. 1997. Budidaya Murbei dan Usaha Persuteraan Alam. Yogyakarta (ID): Kanisius.

Wibowo LR. 2003. Produk Lak NTT: Mampu menembus Amerika. Majalah Kehutanan Indonesia Edisi I.

Wulandari FT. 2012. Gambaran Sistem Kultur Stok Lak dan Teknologi Pasca panen Lak Serta Manfaatnya bagi industri. Media Bina Ilmiah. 6(2):73-77

Wulandari FT. 2014. Strategi peningkatan pasca panen Lak di Desa Sugian Kecamatan Sambellia Kabupaten Lombok Timur. Media Bina Ilmiah. 8(1):68-71. 